\title{
Mitochondrial malic enzyme in Friedreich's ataxia: failure to demonstrate reduced activity in cultured
} fibroblasts

\author{
RGF GRAY,* D KUMAR† \\ From the University Sub-Department of Medical Genetics* and The Centre for Human Genetics, $\dagger$ Sheffield, UK
}

SUMMARY Mitochondrial and cytosolic malic enzymes were assayed radiochemically in fibroblasts from six patients suffering from Friedreich's ataxia in order to verify earlier reports of abnormalities in these enzymes. No abnormalities could be detected in the activities of either enzyme. On cellulose acetate electrophoresis a band of enzyme activity corresponding to the mitochondrial isoenzyme was detectable contrary to earlier reports. Possible explanations for the disparity of results between different laboratories are discussed.

Friedreich's ataxia is a progressive degenerative disorder of the heart and nervous system which follows an autosomal recessive mode of inheritance. It is associated with diabetes mellitus, ${ }^{1}$ and abnormalities in glucose $^{2}$ and pyruvate $^{3}$ metabolism have been reported. However, attempts at identifying specific enzyme defects have led to contradictory results. ${ }^{45}$ Stumpf $e t a l^{6}$ have reported a reduction in the activity of mitochondrial malic enzyme (MEm) (EC 1.1.1.40) in cultured fibroblasts. This enzyme is present in large amounts in human heart and brain tissue and the degree of reduction in activity reported is comparable to that commonly observed in autosomal recessive enzymopathies. Bottacchi and Di Donato ${ }^{7}$ reported a less pronounced deficiency in muscle MEm and presented evidence for the existence of two isoenzymes differing in their cofactor dependence and response to ATP and succinate. Both groups of authors also reported elevated cytosolic malic enzyme activity in Friedreich's ataxia patients. However, Chamberlain and Lewis ${ }^{8}$ reported normal levels of MEm activity in fibroblasts from three patients. Furthermore studies on obligate heterozygotes ${ }^{9}$ have revealed levels of activity substantially lower than the $50 \%$ of normal which would be anticipated. In order to clarify these problems the activity of MEm was measured in fibroblasts from Friedreich's ataxia patients using a new assay technique involving the release of carbon dioxide from radiolabelled malate.

Address for reprint requests: Dr RGF Gray, Centre for Human Genetics, Laughill, 117 Manchester Rd, Sheffield, S10 5DN, UK.

Received 18 May 1984

Accepted 11 June 1984
Furthermore, cellulose acetate electrophoresis was carried out on sonicated cell extracts to test the report $^{6}$ that a MEm band is not visible even when the $\stackrel{p}{p}$ membrane is overloaded with extract.

\section{Patients}

Five previously diagnosed patients with Friedreich's atax were selected from the register of the Friedreich's Atax Group and the records of the Department of Neurology an the Royal Hallamshire Hospital, Sheffield. All the patients were visited personally at their homes and informed consem. obtained for any clinical examinations or the taking of sarf ples. A detailed clinical examination was carried out by one of the co-authors (DK) which in each case confirmed the diagnosis of Friedreich's ataxia. The criteria for diagnosis were cerebellar signs, absent or diminished deep tendon reflexes, muscular weakness of the lower limbs with or without distal muscular wasting, pes cavus and cardiomyopathy. The association of skeletal and cardiac manifestations was not considered essential for the diagnosis of Friedreich's ataxia. Neurophysiological studies of motor and sensory nerve conduction velocities were not performed since all the patients met the criteria for clinical diagnosis. A skin biopsy was taken from the forearm or iliac region for cell culture. Fibroblasts from a previously reported patient ${ }^{10}$ with Friedreich's ataxia were supplied by the MRC Clinical and Population Cytogenetics Unit in Edinburgh.

\section{Methods}

Cells were cultured initially in Ham's F10 with $20 \%$ fetal bovine serum and then transferred on to Eagle's Minimum Essential Medium with added non-essential amino acids and $D$ $10 \%$ fetal bovine serum. All media were buffered with HEPES and contained penicillin $\left(200 \mathrm{uml}^{-1}\right)$ and streptomycin $\left(100 \mu \mathrm{gml}^{-1}\right)$. The cells were routinely screened for $\sigma$ mycoplasma contamination by a microscopic fluorescence 
Table 1 Clinical features of the Friedreich's ataxia patients used in this study

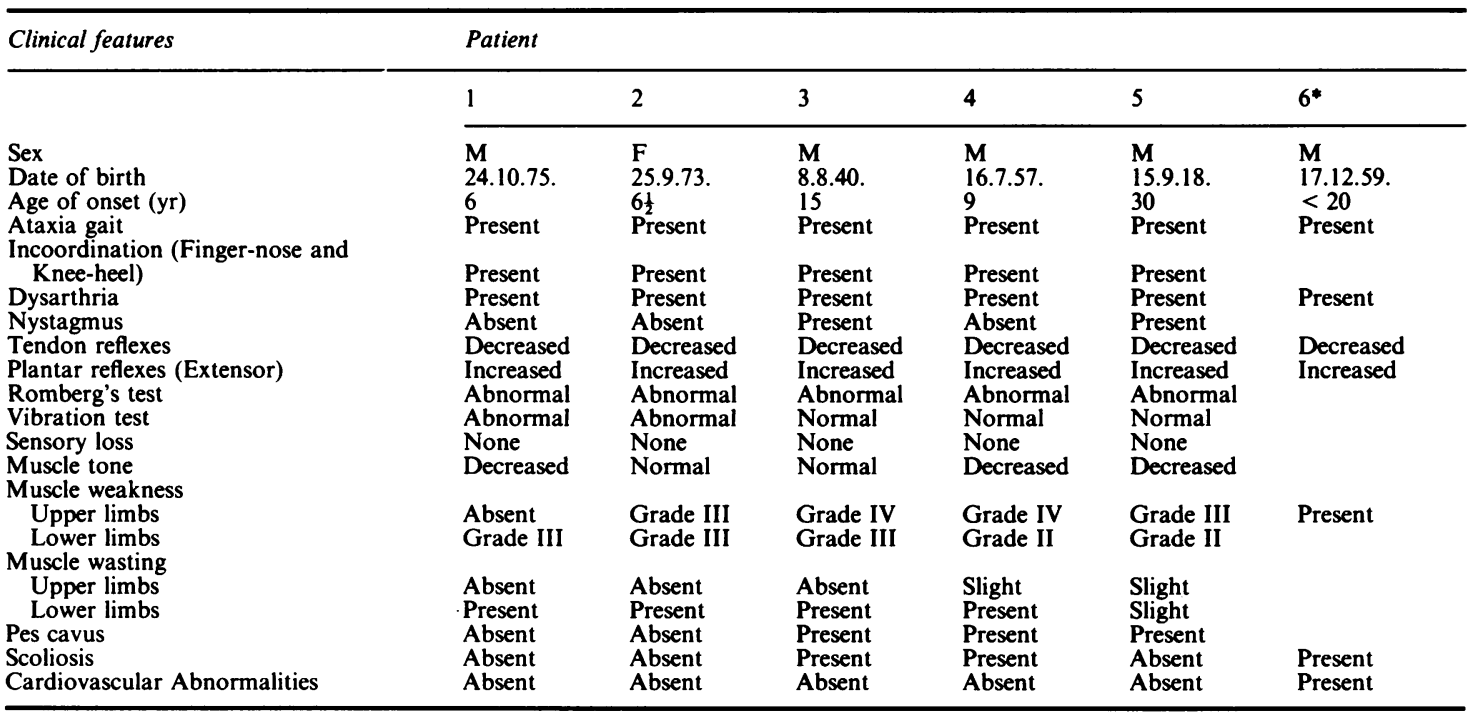

*Taken from Evans et al. ${ }^{10}$

technique. The mitochondria were isolated by a modification of the method of Rhead and Tanaka. ${ }^{11}$ Cells from each line were grown to confluence in eight flasks of $175 \mathrm{~cm}^{2}$ growing area, harvested with trypsin-EDTA and washed twice in isotonic saline. The pellet was resuspended in $2.5 \mathrm{ml}$ of a cold mannitol:tris:EDTA (MTE) solution ( $0.27 \mathrm{~mol}^{-1}$ mannitol, $10 \mathrm{mmol}^{-1}$ tris $\mathrm{HCl}, 0.1 \mathrm{mmol}^{-1}$ EDTA, pH 7.4) with $2.5 \mu \mathrm{g}$ of Protease VII (Sigma Chemical Co. Ltd.) per $400 \mathrm{mg}$ wet weight of cells. After incubation for $90 \mathrm{~s}$ on ice the cells were homogenised with 30 passes of an all glass Duarte homogeniser. The homogenate was centrifuged at $700 \mathrm{~g}$ for 10 minutes and the supernatant centrifuged at $15,000 \mathrm{~g}$ for 10 minutes. The supernatant was removed and used for the assay of cytosolic malic enzyme. The pellet was resuspended in $0.5 \mathrm{ml}$ of a $0.8 \mathrm{mmol} .1^{-1}$ digitonin solution in (MTE) buffer and incubated on ice for 20 minutes. $4 \mathrm{ml}$ of (MTE) buffer was added and the mixture centrifuged at $15,000 \mathrm{~g}$ for 10 minutes. The pellet was washed once in $4 \mathrm{ml}$ (MTE) buffer, resuspended in $0.15 \mathrm{ml}$ of distilled water and sonicated on ice with two 20 second bursts. The sonicate was centrifuged for $10 \mathrm{~min}$ at $33,000 \mathrm{~g}$ and the malic enzyme in all extracts assayed within 2 hours of preparation. Malic enzymes were assayed by determining the release of $\mathrm{CO}_{2}$ from L-(U-C14) malic acid (Amersham International plc). $50 \mu$ l of extract (30-114 $\mu$ g protein) were incubated with $50 \mu \mathrm{l}$ of a pH 7.5 tris buffer containing labelled malate and all relevant cofactors (final concentrations tris $0.235 \mathrm{~mol}^{-1}{ }^{-1}$, NADP $0.2 \mathrm{mmol}^{-1} \mathrm{I}^{-1} \mathrm{MgCl}_{2} 20 \mathrm{mmol}^{-1} \mathrm{I}^{-1}$, mercaptoethanol $2 \mathrm{mmol} .1^{-1}$, L-malate $3 \mathrm{mmol}^{-1}$ at $6 \mathrm{Ci}^{-\mathrm{mol}^{-1}}$ ). Incubations were carried out for 1 hour at $37^{\circ} \mathrm{C}$ in $5 \mathrm{ml}$ serum tubes with circlets of Whatman No. 1 filter paper soaked in $20 \mu \mathrm{l}$ of $3.5 \mathrm{~N} \mathrm{NaOH}$ placed in the caps. It was found that acidification was not necessary in order to achieve total trapping of the released $\mathrm{CO}_{2}$. The papers were counted in a standard scintillation fluid. In order to correct for con- tamination of the mitochondrial fraction with cytosolic malic enzyme (MEc) lactate dehydrogenase activity was measured in both sets of extracts ${ }^{12}$.

Cellulose acetate electrophoresis was performed for 2 hours at $+4^{\circ} \mathrm{C}$ using the conditions described by Stumpf et $a l^{6}$ and enzyme activity visualised by the method of Siebert et al. ${ }^{13}$ The cells from a $175 \mathrm{~cm}^{2}$ flask were harvested, washed, frozen and thawed once in $20 \mathrm{ml}$ of distilled water and sonicated on ice with two 20 second bursts. The sonicate was centrifuged at $33,000 \mathrm{~g}$ and $10 \mu \mathrm{l}$ of the supernatant (71-218 $\mu \mathrm{g}$ of protein) added to the Cellogram II membranes (Shandon Southern Products Ltd.). Protein was measured by the reaction with the Folin-Ciocalteau reagent. All control cell lines were from individuals with no evidence of neurological abnormalities and were of equivalent passage number to the patients' lines.

\section{Results}

The detailed clinical features of the five cases examined by us are given in table 1 . The mean age of onset of symptoms was 10-13 years and two siblings ( 1 and 2) were seen within 6 years of the onset of symptoms. Three patients had marked pes cavus and scoliosis was noted in two. All cases demonstrated absence of deep tendon reflexes and ataxia of both upper and lower limbs. In two cases grade II muscular weakness was noted associated with marked hypotonia in the lower limbs. Three cases showed signs of posterior column involvement whilst a positive Rhomberg's test was observed in five patients. Two cases showed nystagmus. Details of the patient from Edinburgh were obtained from the publication of Evans et al. ${ }^{10}$ This 


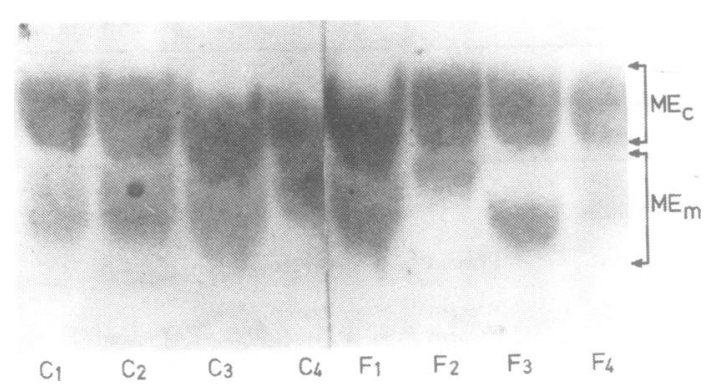

Fig 1 Cellulose acetate electrophoresis of malic enzymes in cultured fibroblasts from Friedreich's ataxia patients and controls.

The enzymes migrate anodally from bottom to top of the figure. The $C$ series are control extracts whilst the $F$ series are extracts from fibroblasts of different Friedreich's ataxia patients.

patient, unlike the five patients we investigated, showed signs of cardiac abnormalities. Apart from patients 1 and 2 who were siblings all the other patients were genetically unrelated.

The assay of MEm and MEc gave substantial radioactive counts $(600-5,000 \mathrm{cpm})$ at the specific activity employed with consistent blank values of approximately $800 \mathrm{cpm}$. The final mitochondrial sonicate contained $0.03-0.70 \%$ cytosolic contamination. This accounted for $5-40 \%$ of the apparent total MEm activity. After correction of the MEm activity for the contribution due to cytosolic $\mathrm{MEc}$ and protein the MEm activity was found to account for from $0 \cdot 53-5 \cdot 1 \%$ of the total activity. In view of the small contribution MEm contamination would make to the $\mathrm{MEc}$ activity a mitochondrial marker enzyme was not used to correct the latter. Table 2 shows the results of assays of MEm and MEc on cells from the patients and the controls. When values were assessed by a Student $t$ test no significant differences could be found between the patients and controls in terms of corrected or uncorrected MEm MEc or the ratio of $\mathrm{MEm} / \mathrm{MEc}$ specific activities for each individual. In terms of MEm and MEc individually all values for the patients were within the control range. With the $\mathrm{MEm} / \mathrm{MEc}$ ratios only one value was slightly below the normal range.

Electrophoresis of sonicates from five of the patients including patient 6 revealed a distinct MEm band (fig). This band showed the polymorphism characteristic of human MEm and migrated in the same position as that of a reference human brain sample. The band was still present after incubation of one Friedreich's ataxia line and a control line in stain containing 2.5 m.mol.1 ${ }^{-1}$ ATP although it was difficult to assess whether there had been a specific reduction in intensity.

\section{Discussion}

The failure to demonstrate either a reduction in MEm activity or an elevation in MEc activity is in agreement with Chamberlain and Lewis ${ }^{8}$ but at variance with Stumpf et $a l^{6}$ and Bottachi and Di Donato. ${ }^{7}$ There are a number of possible explanations for these disparities.

Firstly there may be differences between the authors in the criteria for defining Friedreich's ataxia. Certainly Friedreich's ataxia is a disorder which can easily be misdiagnosed and there is a plethora of criteria by which to define it reported in the literature. ${ }^{14-16}$ This is why we believe it is necessary to report details of the clinical features of the cases used in studies on this disease. Our patients fitted the prime criteria of reduced tendon reflexes and ataxic gait. Together with the other abnormalities reported we are confident that this picture represents classic Friedreich's ataxia even though one patient showed his first symptoms at 30 years of age.

Secondly it may be that there is genetic heterogeneity within Friedreich's ataxia which is expressed on a geographical basis. Certainly inherited diseases classified on clinical grounds have often been later sub-divided on the basis of investigations of the prit mary biochemical defects. Such a possibility is testab by the exchange of material between groups different countries.

A third possibility is that technical artefacts have led to the disparities. The assay used by Stumpf et of follows the formation of NADPH and there are number of other enzymes within the cell capable of reducing NADP. However, Chamberlain and Lewis measured this parameter in their assays and the stain used in the electrophoretic method reported here also detects NADPH formation. Thus it seems unlikely that the assay is the source of the problem. The values for the specific activity of MEm reported here are approximately $15 \%$ of those reported by Stumpf et al ${ }^{6} \mathbb{\perp}$ and Chamberlain and Lewis. ${ }^{8}$ This is partly a result of $\overrightarrow{\overline{7}}$ the lower substrate concentration used and correction

Table 2 Malic enzyme activities in cultured fibroblasts from Friedreich's ataxia patients

\begin{tabular}{|c|c|c|c|c|}
\hline & \multicolumn{4}{|c|}{$\begin{array}{l}\text { pmoles } \mathrm{CO}_{2} \cdot \min ^{-1} \cdot m^{-1} \text { protein } \\
\text { Mean }(+S D)\end{array}$} \\
\hline & $\begin{array}{l}\text { MEm } \\
\text { (Un- } \\
\text { corrected) }\end{array}$ & $\begin{array}{l}\text { MEm } \\
\text { (Corrected) }\end{array}$ & $M E c$ & $M E m / M E c$ \\
\hline Controls(7) & $\begin{array}{l}186( \pm 120) \\
(63.4-342)\end{array}$ & $\begin{array}{l}173( \pm 110) \\
(54 \cdot 9-314)\end{array}$ & $\begin{array}{l}645( \pm 310) \\
(293-1226)\end{array}$ & $\begin{array}{l}0.287( \pm 0.176) \\
(0.078-0.520)\end{array}$ \\
\hline Patients(6) & $\begin{array}{l}202( \pm 85) \\
(92 \cdot 4-305)\end{array}$ & $\begin{array}{l}182( \pm 91) \\
(69 \cdot 3-287)\end{array}$ & $\begin{array}{l}671( \pm 188) \\
(488-1011)\end{array}$ & $\begin{array}{l}0.292( \pm 0.153) \\
(0.069-0.471)\end{array}$ \\
\hline
\end{tabular}

All assays were performed in duplicate 
for this based on the published kinetic parameters of human $\mathrm{MEm}^{17}$ gives values $25 \%$ of that of Stumpf $e t$ $a l^{6}$ This may indicate that the dehydrogenation assay is measuring dehydrogenases other than malic enzyme. The decarboxylation assay should be inherently very specific since malic enzyme is the only human enzyme known to decarboxylate L-malate. A further complication is the report by Bottachi and Di-Donato ${ }^{7}$ that there exists in human muscle mitochondria a malic enzyme which can utilise NAD and NADP, shows sigmoidal kinetics, is inhibited by ATP and is activated by succinate. This work follows earlier reports of the existence of such an izoenzyme in bovine adrenals ${ }^{18}$ rabbit heart, ${ }^{19}$ rat liver $^{20}$ and human placenta. ${ }^{21}$ It is not clear whether this enzyme exists in human fibroblasts and if so, in what proportion it is to total MEm activity. Certainly the failure to demonstrate substantial ATP inhibition indicates that it is not the predominant isoenzyme. Bottachi and $\mathrm{Di}$ Donato ${ }^{7}$ indicate that it is the non-NAD dependent isoenzyme which is deficient in Friedreich's ataxia muscle suggesting the possibility that slight differences between culture conditions and separation procedures could lead to preferential inactivation/enrichment of one isoenzyme or the other. However the culture conditions used were very similar to those reported by Stumpf et al. ${ }^{6}$ Differences due to variations in the degrees of confluence when the cells were harvested are unlikely since our cells were harvested when at confluence whilst those used by Chamberlain and Lewis were harvested in the logarithmic growth phase (S Chamberlain-personal communication). In one experiment the isolation method reported by Stumpf $e t$ al $^{6}$ was used on a control line and the assay performed with a similar substrate concentration. The values obtained were within the control range previously established. Despite these observations, the possibility exists that slight variations in culture conditions or isolation procedures may dramatically influence the MEm isoenzyme pattern.

Finally it needs to be stressed that all cell lines should be tested for mycoplasma-contamination by a reliable non-microbiological method as this can lead to spurious results in various enzymological tests.

Friedreich's ataxia has proved to be a difficult disorder to define as an enzymopathy. This is probably partly due to problems in accurately defining clinical diagnostic criteria, cell culture conditions and assay methodology. If indeed it is caused by an inherited enzyme deficiency then it will have proved to be one of the most difficult to define of all the inborn errors of metabolism.

This work was supported by the Friedreich's Ataxia Group. We thank Professor HJ Evans and Karin E
Buckton of the MRC Clinical and Population Cytogenetics Unit in Edinburgh for supplying the cells from patient 6 and the staff at the Centre for Human Genetics, Sheffield for growing cells from the skin biopsies.

\section{References}

${ }^{1}$ Hewer RL, Robinson N. Diabetes mellitus in Friedreich's ataxia. J Neurol Neurosurg Psychiatry 1968;31:226-31.

${ }^{2}$ Purkiss P, Baraitser M, Borud O, Chalmers RA. Biochemical and clinical studies of Friedreich's ataxia. J Neurol Neurosurg Psychiatry 1981;44:574-82.

${ }^{3}$ Livingstone IR, Mastaglia FL, Pennington RJT. An investigation of pyruvate metabolism in patients with cerebellar and spinocerebellar ataxias. J Neurol Sci 1980;48:123-32,

${ }^{4}$ Blass JP, Kark RAP, Menon NK. Low activities of the pyruvate and oxoglutarate dehydrogenase complexes in five patients with Friedreich's ataxia. $N$ Engl J Med 1976;295:62-7.

${ }^{5}$ Stumpf DA, Parks JK. Friedreich's ataxia II. Normal kinetics of lipoamide dehydrogenase. Neurology (Minneap) 1979;29:820-6.

${ }^{6}$ Stumpf DA, Parks JK, Eguren LA, Haas R. Friedreich ataxia; III. Mitochondrial malic enzyme deficiency Neurology (NY) 1982;32:221-7.

${ }^{7}$ Bottachi E, Di Donato S. Skeletal muscle NAD ${ }^{+}(\mathrm{P})$ and $\mathrm{NAD}^{+} \mathbf{P}-$ dependent malic enzymes in Friedreich's ataxia. Neurology (NY) 1983;33:712-6.

${ }^{8}$ Chamberlain S, Lewis PD. Normal mitochondrial malic enzyme levels in Friedreich's ataxia fibroblasts. $J$ Neurol Neurosurg Psychiatry 1983;46:1050-1.

${ }^{9}$ Stumpf DA, Parks JK, Davis-Parker W. Friedreich's disease: IV Reduced mitochondrial malic enzyme activity in heterozygotes. Neurology (NY) 1983;33:780-3.

${ }^{10}$ Evans HJ, Vijayalaxmi, Pentland B, Newton MS. Mutagen hypersensitivity in Friedreich's ataxia. Ann Hum Genet 1983;47:193-204.

${ }^{11}$ Rhead, WJ, Tanaka K. Demonstration of a specific mitochondrial isovaleryl CoA dehydrogenase deficiency in fibroblasts from patients with isovaleric acidaemia. Proc Natl Acad Sci USA 1980;77:580-3.

12 Bergmeyer, HU, Bernt E. Lactate Dehydrogenase. In Bergmeyer HU, ed. Methods of Enzymatic Analysis Vol. II, Academic Press Inc 1974:574-8.

${ }^{13}$ Siebert G, Ritter H, Kompf J. Mitochondrial malic enzyme in human leukocytes: Formal genetics and population genetics. Hum Genet 1979;51:319-22.

14 Barbeau A. Friedreich's Disease 1982: Etiologic Hypotheses. A personal analysis. Can J Neurol Sci 1982;9:243-63.

${ }^{15}$ Harding AE. Classification of the hereditary ataxias and paraplegias. Lancet 1983;(i):1151-5.

${ }^{16}$ Ackroyd RS, Finnegan JA, Green SH. Friedreich's ataxia. A clinical review with neurophysiological and echocardiographic findings. Arch Dis Childh 1984;59:217-21.

${ }^{17}$ Burchell A, Crosby A, Wade Cohen PT. Human mitochondrial malic enzyme variants: properties of the different polymorphic forms. Ann Hum Genet 1977;41:1-7.

${ }^{18}$ Sauer LA. Mitochondrial NAD-dependent malic 
enzyme: A new regulatory enzyme. Febs Lett 1973;33:251-5.

${ }^{19}$ Lin RC, Davis EJ. Malic enzymes of rabbit heart mitochondria. J Biol Chem 1974;249:3867-75.

${ }^{20}$ Sauer LA. An NAD - and NADP dependent malic enzyme with regulatory properties in rat liver and adre- nal cortex mitochondrial fractions. Biochem Biophys Res Commun 1973;50:524-31.

${ }^{21}$ Swierczynski J, Scisiowski P, Aleksandrowicz Z, Zelewski L. NAD(P)-Dependent malic enzyme activity in human term placenta mitochondria. 1982;28:247-55. 